Systematic Review

\title{
Linear Accelerator Stereotactic Radiosurgery for Trigeminal Neuralgia
}

Leonor Varela-Lema, PhD1', Marisa López-García, MD1', Maria Maceira-Rozas, MPH, and Victor Muñoz-Garzón, MD²

From: ${ }^{1}$ Galician Agency for Health

Technology Assessment (Axencia de Avaliación de Tecnoloxías Sanitarias de Galicia, Galician Health Authority, Santiago de Compostela, Spain; ${ }^{2}$ Radiation Oncology Department, Meixoeiro HospitalVigo University Teaching Hospital Complex, Vigo, Spain

Address Correspondence: Dr. Leonor Varela Axencia de Avaliación de Tecnoloxías Sanitarias de Galicia Consellería de Sanidade Edif. Administrativo de San Lázaro. San Lázaro s/n 15781 Santiago de Compostela, Spain.

E-mail: avalia-tı@sergas.es leonor.varela.lema@sergas.es

Disclaimer: There was no external funding in the preparation of this manuscript.

Conflict of interest: Each author certifies that he or she, or a member of his or her immediate family, has no commercial association (i.e., consultancies, stock ownership, equity interest, patent/licensing arrangements, etc.) that might pose a conflict of interest in connection with the submitted manuscript.

Manuscript received: 03-03-2014 Revised manuscript received: 07-24-2014 Accepted for publication: 09-11-2014

Free full manuscript: www.painphysicianjournal.com
Background: Stereotactic radiosurgery is accepted as an alternative for patients with refractory trigeminal neuralgia, but existing evidence is fundamentally based on the Gamma Knife, which is a specific device for intracranial neurosurgery, available in few facilities. Over the last decade it has been shown that the use of linear accelerators can achieve similar diagnostic accuracy and equivalent dose distribution.

Objectives: To assess the effectiveness and safety of linear-accelerator stereotactic radiosurgery for the treatment of patients with refractory trigeminal neuralgia.

Methods: We carried out a systematic search of the literature in the main electronic databases (PubMed, Embase, ISI Web of Knowledge, Cochrane, Biomed Central, IBECS, IME, CRD) and reviewed grey literature. All original studies on the subject published in Spanish, French, English, and Portuguese were eligible for inclusion. The selection and critical assessment was carried out by 2 independent reviewers based on pre-defined criteria. In view of the impossibility of carrying out a pooled analysis, data were analyzed in a qualitative way.

Results: Eleven case series were included. In these, satisfactory pain relief (BIN I-IIIb or reduction in pain $\geq 50$ ) was achieved in $75 \%$ to $95.7 \%$ of the patients treated. The mean time to relief from pain ranged from 8.5 days to 3.8 months. The percentage of patients who presented with recurrences after one year of follow-up ranged from $5 \%$ to $28.8 \%$. Facial swelling or hypoesthesia, mostly of a mild-moderate grade appeared in $7.5 \%-51.9 \%$ of the patients Complete anaesthesia dolorosa was registered in only study $(5.3 \%)$. Cases of hearing loss $(2.5 \%)$, brainstem edema (5.8\%), and neurotrophic keratoplasty $(3.5 \%)$ were also isolated.

Conclusions: The results suggest that stereotactic radiosurgery with linear accelerators could constitute an effective and safe therapeutic alternative for drug-resistant trigeminal neuralgia. However, existing studies leave important doubts as to optimal treatment doses or the therapeutic target, long-term recurrence, and do not help identify which subgroups of patients could most benefit from this technique.

Limitations: Paucity of literature and clear lack of clarification for clinical utilization of this technique.

Key words: Radiosurgery, trigeminal neuralgia, functional radiosurgery, radiation therapy of benign diseases, stereotactic radiotherapy

Pain Physician 2015; 18:15-27

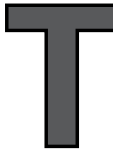
rigeminal neuralgia (TN) is defined as "a unilateral painful disorder that is characterised by brief, electric-shock-like pains, is abrupt in onset and termination, and is limited to the distribution of one or more divisions of the trigeminal nerve" $(1,2)$. It is estimated that TN might affect 1 to 2 persons per
10,000 population $(1,3,4)$, with onset mainly between 50 and 70 years of age. Neuralgias are idiopathic in $90 \%$ of cases, and the most widely accepted theory postulates that the pain might be the consequence of proximal compression or deformation of the trigeminal nerve root close to the brainstem (dorsal 
root entry zone) by a tortuous or ectasic blood vessel. TN is regarded as symptomatic in cases where presentation is secondary to neoplasms, multiple sclerosis lesion plaques, or other abnormalities that invade the nerve or its pathways.

Drug treatment with anticonvulsants is the first therapeutic step for control of pain in TN. It has been shown that carbamazepine can achieve complete or almost complete control of pain in $58 \%-100 \%$ of patients and adequate relief in $70 \%-80 \%$ of cases (5). Nevertheless, the use of this and other second-line drugs (oxcarbazepine, baclofen, etc.) is complicated by the adverse side effects that these cause $(2,6)$, and $25 \%-50 \%$ of patients become drug-resistant as TN progresses.

Different surgical treatments are considered for these patients, none totally effective to achieve longterm complete pain relief with minimal side effects and complications. The main procedures that have been applied are microvascular decompression (MVD) and percutaneous rhizotomy at the gasserian ganglion level, i.e., percutaneous microcompression with a Fogarty balloon catheter, radiofrequency thermocoagulation (RFT), and glycerol rhizotomy (GR) $(2,3)$. MVD achieves long-lasting pain relief in around $70 \%$ of these patients (7) but has an average mortality of $0.2 \%$ and up to around $4 \%$ of patients suffer from severe complications (cerebrospinal fluid leak, stroke, hematoma). Hearing loss is common and can occur in as many as $10 \%$ of cases (5). In general terms, percutaneous rhizotomy procedures are less invasive and achieve initial pain relief in over $90 \%$ of patients but are characterized by high rates of recurrences and motor and/or sensory disturbances, inherent to the technique. Although most of these side effects are transient, permanent sensory loss can affect more than $30 \%$ of patients treated with RFT and approximately $20 \%$ of patients treated with BC suffer from severe numbness $(8,9)$. Masseter muscle weakness can cause long-term mastication disturbances in $10 \%$ or more of the patients after BC or RFT and corneal numbness can amount to $20 \%$ in some RFT studies $(7,9,10)$.

The first time that radiotherapy was used as an alternative in the treatment of TN was in 1897 by Hermann Moritz Gocht (11), with good results which were subsequently confirmed by other clinicians in the early part of the twentieth century. Until this time, treatment was mainly medical and consisted of purging, pills of conium maculatum, muriate of mercury, ether, opium and arsenic gruel, among others (12). In the 1960s ioniz- ing radiations targeted at a stereotactic - site - stereotactic radiosurgery (SRS) - began to be used to create lesions in the trigeminal ganglion and adjacent root. Since 1991, this technique has been widely applied and the results of many observational studies suggest that this technique can offer a similar pain relief in the short-term with fewer severe complications than MVD or percutaneous procedures, although pain relief is not immediate and the recurrence rate is deemed to be higher $(41 \%, 34 \%$, and $22 \%$ at 3,5 , and 7 years, respectively) than that recorded for other surgical options (1,13-15). Existing evidence is, however, based on the Gamma Knife ${ }^{\circledast}$ (GK), which is a specific device for the treatment of cranial lesions, something that limits generalized access and means that this option may not be available at all hospitals.

It has recently been proposed that, with the adaptation of linear accelerators (LINACs), equivalent clinical results could be achieved for SRS used as a secondary or primary surgical procedure. Hence, the first reported series with modern accelerators (16) shows that the effectiveness of LINAC-based stereotactic radiosurgery as a first-line procedure improved by $95.5 \%$ in terms of pain, $68.1 \%$ in terms of complete response without medication, $36.3 \%$ in terms of mild hypoaesthesia/ paraesthesia, and $23.8 \%$ in terms of complications and recurrence of pain.

Accordingly, the study aim was to conduct a systematic review to assess the effectiveness and safety of SRS using LINACs for the treatment of drug-resistant TN patients, while evaluating the benefit-risk profile with respect to the GK and other ablative and non-ablative surgical procedures (effectiveness, safety, and costs).

\section{Methods}

We carried out an exhaustive systematic search of the medical literature until October 2013, covering key international general health care databases commonly used to identify published articles (PubMed, Embase, Biomed Central), systematic reviews and health technology assessments (University of York Center for Reviews and Dissemination, Cochrane Library), and ongoing trials (ClinicalTrials.gov, Current Controlled Trials, Centre Watch, and the National Research Register Archive). In addition, we used the ISI Web of Knowledge search engine to search multiple databases of published and unpublished literature simultaneously (Web of Science journal listings, patents, conference proceedings, websites) and searched databases that concentrate all the literature produced in Spain, Índice Bibliográfico Espa- 
ñol en Ciencias de la Salud (IBECS), Índice Médico Español (IME), and includes journals not indexed elsewhere. Specific search strategies were drawn up for each of the databases, combining the following key words and free text terms: "stereotactic"; "radiosurgery"; "linear accelerator"; "LINAC"; and "trigeminal neuralgia." To retrieve additional unpublished data, we performed a general Internet search, completed with a manual review of the bibliographic references cited in the papers selected.

Two independent reviewers selected the papers in accordance with pre-defined inclusion and exclusion criteria; discrepancies were resolved by discussion (Table 1). For assessment purposes, we considered all original studies published in peer review scientific journals in Spanish, French, English, and Portuguese, which furnished primary data on the effectiveness and safety of this procedure. With the exception of single-case series, no exclusion criteria were established in terms of sample size.

Reported data were individually extracted using a data-extraction form and in view of the impossibility of performing a meta-analysis, studies were analyzed in a qualitative way. Information was synthesized in evidence tables and displayed in plain text format. Risk of bias was evaluated using the AHRQ checklist (17). The level of evidence was established using the Scottish Intercollegiate Guidelines Network (SIGN) scale (18). This scale, developed for facilitating recommendation making in systematic review based guidelines, allows for differentiating judgments based on strong evidence and those based on weak evidence. The level of evidence is determined based on an objective assessment of the design and quality of each study and a more subjective assessment of the consistency, clinical relevance, and applicability of the whole body of evidence (Table 2).

\section{Results}

\section{Bibliographic Search Results}

The primary search of biomedical literature databases yielded a total of 678 bibliographic references. After a review of the titles and/or abstracts, all 34 original studies published in scientific journals that were deemed to comply with selection criteria were considered for full-text appraisal. Of these, 23 were excluded after reading the full-text because they did not meet the inclusion/exclusion criteria. Fig. 1 shows the paper selection process and the reasons for excluding potentially relevant papers.

\section{Effectiveness Results}

The most recent study, published by Fraioli et al (19) in 2012, provided a comparison between the outcomes of patients treated with a single 40Gy dose of radiosurgery ( $n=23$ patients with severe TN) and those of patients treated with equivalent doses of hypofractionated stereotactic radiotherapy (HFSRT) ( $n=22$ patients with moderate or severe TN). In the group treated with SRS, complete pain relief requiring no medication was achieved in $43.5 \%$ of patients (BNI I, Table 3), 39.1\% presented with occasional pain

Table 1. Study selection criteria.

\begin{tabular}{|l|l|}
\hline Aspect considered & Inclusion/exclusion criteria \\
\hline Language & Studies in Spanish, French, English, and Portuguese were included. \\
\hline Type of publication & $\begin{array}{l}\text { For analysis purposes, original studies published in scientific journals with external peer review were considered. } \\
\text { Abstracts or proceedings of meetings, symposia and congresses, letters to the editor, and unpublished data were } \\
\text { excluded. }\end{array}$ \\
\hline Study design & $\begin{array}{l}\text { Systematic reviews, meta-analyses, clinical trials, cohort studies, case-control studies, cross-sectional studies, and } \\
\text { case series were included. } \\
\text { Narrative reviews were excluded. }\end{array}$ \\
\hline Patient characteristics & $\begin{array}{l}\text { Studies were included that assessed patients with TN who were resistant to drugs or did not tolerate medical } \\
\text { treatment due to adverse side-effects. }\end{array}$ \\
\hline Type of intervention & $\begin{array}{l}\text { Studies that assessed SRS systems using a LINAC (adapted or unadapted; with or without stereotactic frame) were } \\
\text { included. } \\
\text { Other types of radiosurgery (GK, proton beam radiosurgery) or robotic systems (CyberKnife) were excluded. }\end{array}$ \\
\hline Sample size & Single-case studies were excluded. \\
\hline Follow-up time & No limits were set. \\
\hline Results & $\begin{array}{l}\text { Studies that provided data on the effectiveness (pain control), safety (complications and/or short- or long-term } \\
\text { adverse side-effects of the procedure), or costs were considered. }\end{array}$ \\
\hline
\end{tabular}


Table 2. Key to evidence statements and grades of recommendations SIGN 50.

\begin{tabular}{|c|l||}
\hline \multicolumn{2}{|l||}{ LEVELS OF EVIDENCE } \\
\hline $1++$ & High quality meta-analyses, systematic reviews of RCTs, or RCTs with a very low risk of bias \\
\hline $1+$ & Well conducted meta-analyses, systematic reviews, or RCTs with a low risk of bias \\
\hline $1-$ & Meta-analyses, systematic reviews, or RCTs with a high risk of bias \\
\hline $2++$ & $\begin{array}{l}\text { High quality systematic reviews of case control or cohort studies } \\
\text { High quality case control or cohort studies with a very low risk of confounding or bias and a high probability that the relationship } \\
\text { is causal }\end{array}$ \\
\hline $2+$ & $\begin{array}{l}\text { Well conducted case control or cohort studies with a low risk of confounding or bias and a moderate probability that the } \\
\text { relationship is causal }\end{array}$ \\
\hline $2-$ & Case control or cohort studies with a high risk of confounding or bias and a significant risk that the relationship is not causal \\
\hline 3 & Non-analytic studies, e.g., case reports, case series \\
\hline 4 & Expert opinion \\
\hline
\end{tabular}

\section{GRADES OF RECOMMENDATIONS}

\begin{tabular}{|c|l|}
\hline A & $\begin{array}{l}\text { At least one meta-analysis, systematic review, or RCT rated as 1++, and directly applicable to the target population; or a body } \\
\text { of evidence consisting principally of studies rated as 1+, directly applicable to the target population, and demonstrating overall } \\
\text { consistency of results }\end{array}$ \\
\hline B & $\begin{array}{l}\text { A body of evidence including studies rated as 2++, directly applicable to the target population, and demonstrating overall } \\
\text { consistency of results; or extrapolated evidence from studies rated as 1++ or 1+ }\end{array}$ \\
\hline C & $\begin{array}{l}\text { A body of evidence including studies rated as 2+, directly applicable to the target population and demonstrating overall } \\
\text { consistency of results; or extrapolated evidence from studies rated as 2++ }\end{array}$ \\
\hline D & Evidence level 3 or 4; or extrapolated evidence from studies rated as 2+ \\
\hline
\end{tabular}

Source: Scottish Intercollegiate Guidelines Network. Forming guideline recommendations. In: SIGN 50: A Guideline Developers' Handbook. SIGN, Edinburgh, 2011. www.sign.ac.uk/pdf/sign50.pdf (46)

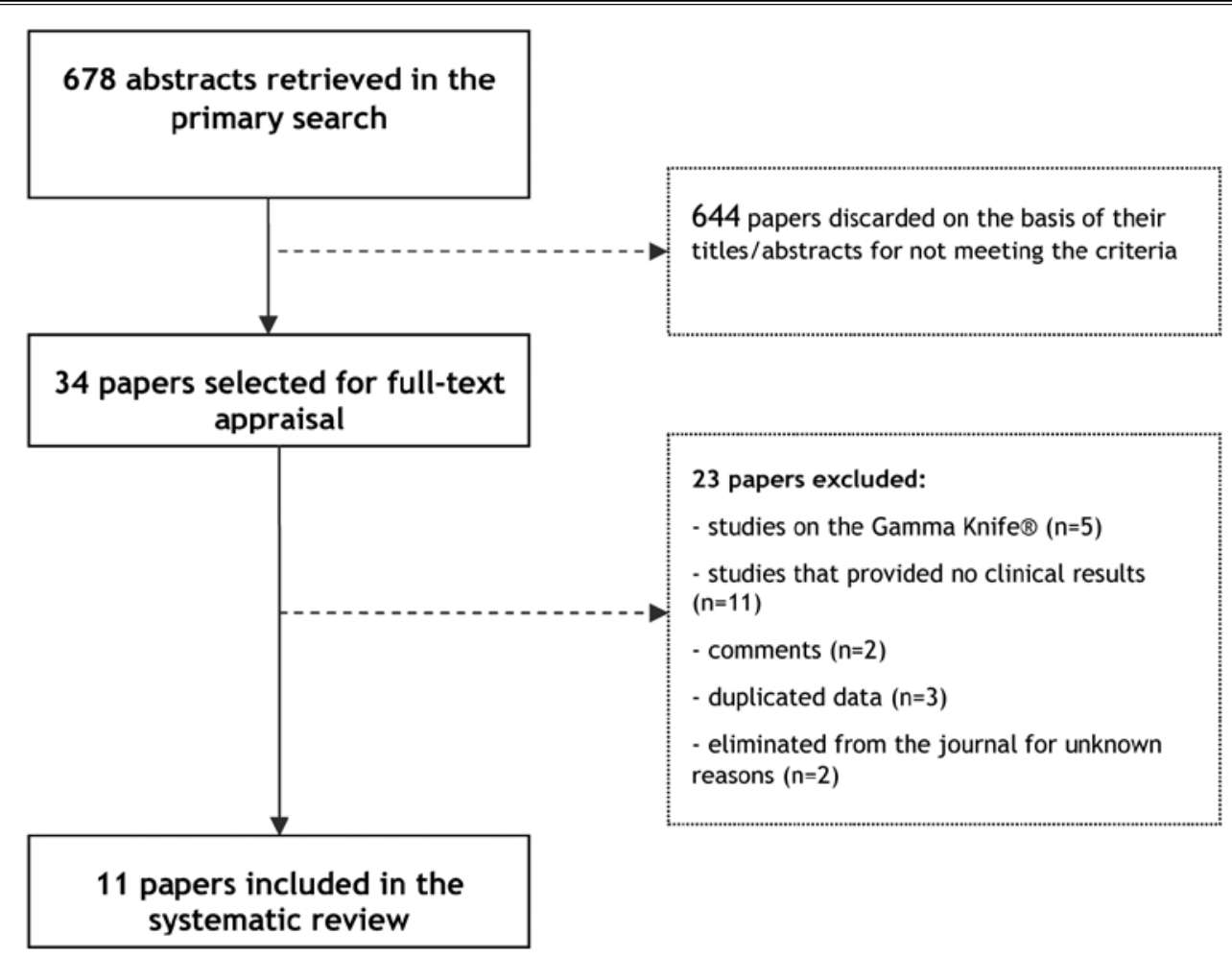

Fig. 1. Results of the bibliographic search. 
not requiring medication (BNI II), 8.7\% achieved complete pain relief with medication (BNI IIIa), and $4.3 \%$ presented with mild pain adequately controlled with medication (BNI IIIb): $27.3 \%$ presented with recurrences during follow-up (mean 3.1 years). In the group that received HFSRT, the equivalent improvements were $36.4 \%, 36.4 \%, 18.2$, and $9.1 \%$, respectively: these improvements were maintained across follow-up (mean 4.2 years).

Smith et al (20) reported in 2011 a retrospective analysis of 179 patients treated from August 1995 to January 2008 at the David Geffen School of Medicine in Los Angeles, and assessed how outcomes had been influenced by indication, dosage (70Gy to 90Gy), and target (surface of the brain stem: the $30 \%$ isodose line (IDL) or the $50 \%$ IDL) (Table 4). They observed significant improvements in pain (relief $>50 \%$ or complete relief with reduction of medication) in $88.5 \%$ of patients with idiopathic neuralgias $(n=130)$, in $68 \%$ of secondary cases $(n=28)$, and in $27.3 \%$ of atypical cases $(n=11)$, with these results being maintained by $93.9 \%$ of patients $(n=115)$ at 12 months and by $82.6 \%$ of patients at 36 months. Patients who were treated with 90Gy and the brainstem target close to the $50 \%$ IDL obtained better results than did patients treated with 70 Gy to the $30 \%$ IDL or 90 Gy to the $30 \%$ IDL $(P>0.005)$. Mean time of recurrence was 12.6 months. Relapses were more frequent and appeared earlier in the group that had undergone prior surgical interventions $(27.8 \%$ at 10.1 months versus $14.5 \%$ at 20.9 months; $P=0.032$ ).

A paper from the same year published by Dos Santos et al (21) analyzed the repercussions of change in the therapeutic management of 52 patients with essential TN who were treated from January 1998 to December 2009 at Madrid's Gregorio Marañón Hospital (dose $\leq 70 \mathrm{~Gy}$ versus $>70 \mathrm{~Gy}$, changes in the therapeutic target and an increase in the number of collimators). They found that $17.3 \%$ of patients achieved complete pain relief without medication and $40.4 \%$ achieved complete pain relief with medication. Pain relief was not related with the focal point or target, number of collimators, or dose used $(P>0.005)$. After a mean follow-up of 26.6 months ( $6.3-99.9$ months), $28.8 \%$ of patients presented with relapses.

Chen JC et al (22) reported different experiences at a single health center, the Ninth People's Hospital in Shanghai, using different devices and treatment guidelines. The most recent publication from this group (2010) described the outcomes of 44 patients treated using the Brain Lab Novalis Exac Trac (Brain
Table 3. Barrow Neurological Institute (BNI) pain intensity score.

\begin{tabular}{|c|l|}
\hline \multicolumn{2}{|c|}{ Score } \\
\hline I & No trigeminal pain, no medication \\
\hline II & Occasional pain, not requiring medication \\
\hline III & Some pain, adequately controlled with medication \\
\hline IV & Some pain, not adequately controlled with medication \\
\hline V & Severe pain/no pain relief \\
\hline
\end{tabular}

Source: Pusztaszeri M, Villemure JG, Regli L, Do HP, Pica A. Radiosurgery for trigeminal neuralgia using a linear accelerator with BrainLab system: Report on initial experience in Lausanne, Switzerland. Swiss Med Wkly 2007; 137:682-686 (27).

Lab) robotic positioning system, with maximum doses of $90 \mathrm{~Gy}$ applied at the level of the cisternal segment of the trigeminal nerve: $91 \%$ reported satisfactory results ( $\leq \mathrm{BNI}$ IIIb) and $25 \%$ complained of recurrence of pain $(n=11)$. The paper published in 2008 (23) reported the results of 82 patients treated with the guidance of an invasive stereotactic frame, with maximum doses of 85 - 90Gy being applied in the case of first radiosurgical interventions and doses of 60Gy in the case of reinterventions. An $85 \%$ efficacy ( $\leq$ BNI IIlb) and a $15 \%$ failure rate (BNI IV or V) were recorded. There was a significant correlation between these results and the existence of a prior response to anticonvulsants $(P=0.0039)$. Success showed no correlation with the pattern of pain, focal point, or application of prior surgical procedures. A total of 16 patients $(19.3 \%)$ presented with recurrences across follow-up. The first patients treated at this hospital (November 2002 to November 2003) with this dosage protocol (24) displayed excellent to good results in $78 \%$ (BNI I-III), acceptable results in $9 \%$ (BNI IV), and treatment failure in $12.5 \%$ of cases (BNI V). Mean time to disappearance of pain was 6 weeks. Improvement in pain was associated with a previous response to carbamazepine $(P<0.05)$ but not with prior procedures; $6.2 \%(n=2)$ of patients presented with relapses.

Also in 2010, Chen MJ et al (25) described the experience at Shanghai's Ninth People's Hospital using doses of 70Gy targeted at the trigeminal ganglion. Of 40 patients with essential TN treated and followed up for a mean of 7.9 months, $16(40 \%)$ presented with excellent pain relief, 17 (42.5\%) with good relief, and 7 $(17.5 \%)$ with poor relief. Mean time to appearance of improvement was 12.5 days. One of the patients who improved significantly $(n=33)$ presented with recurrent pain (3\%). 
Pain Physician: January/February 2015; 18:15-27

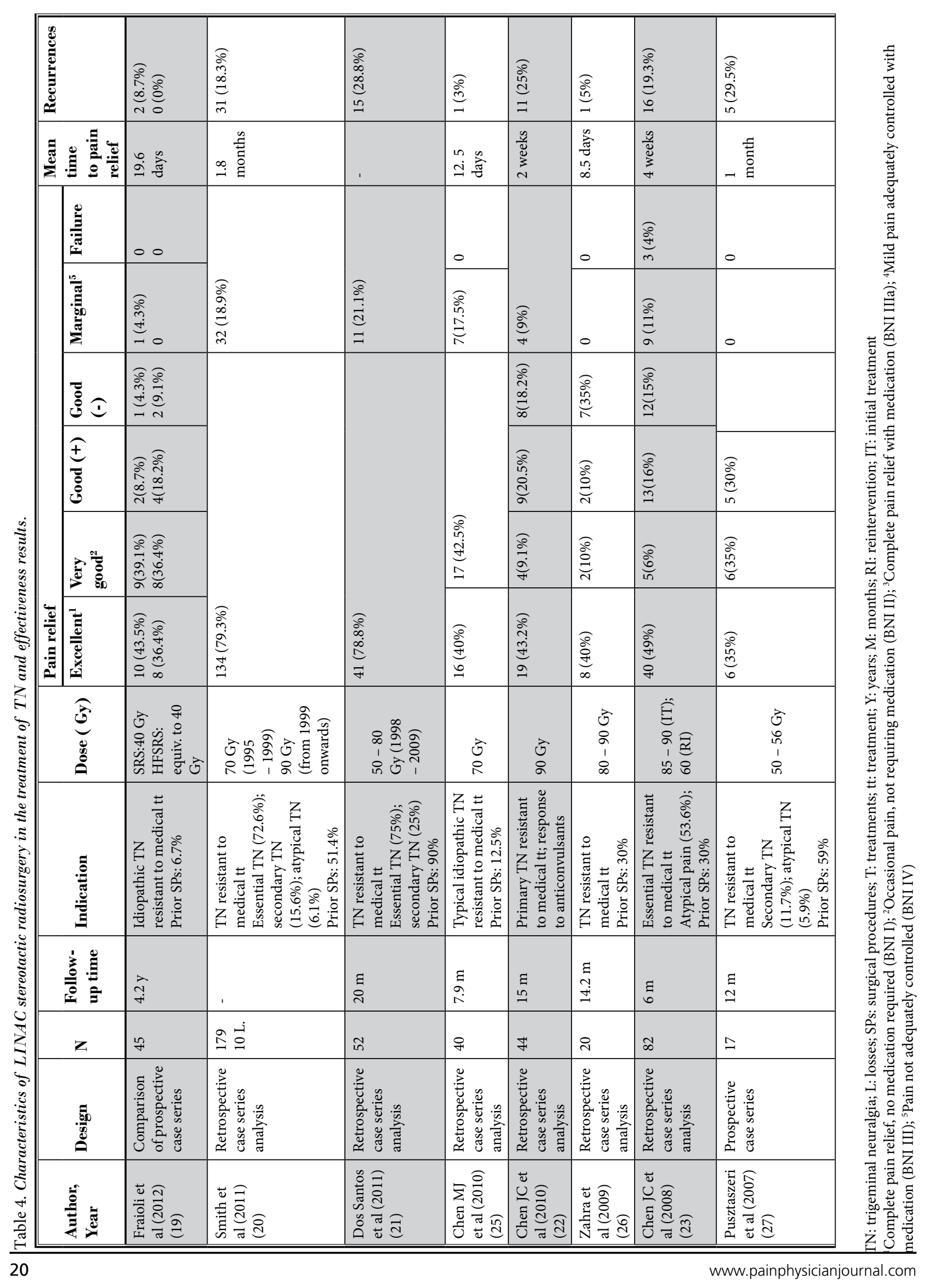




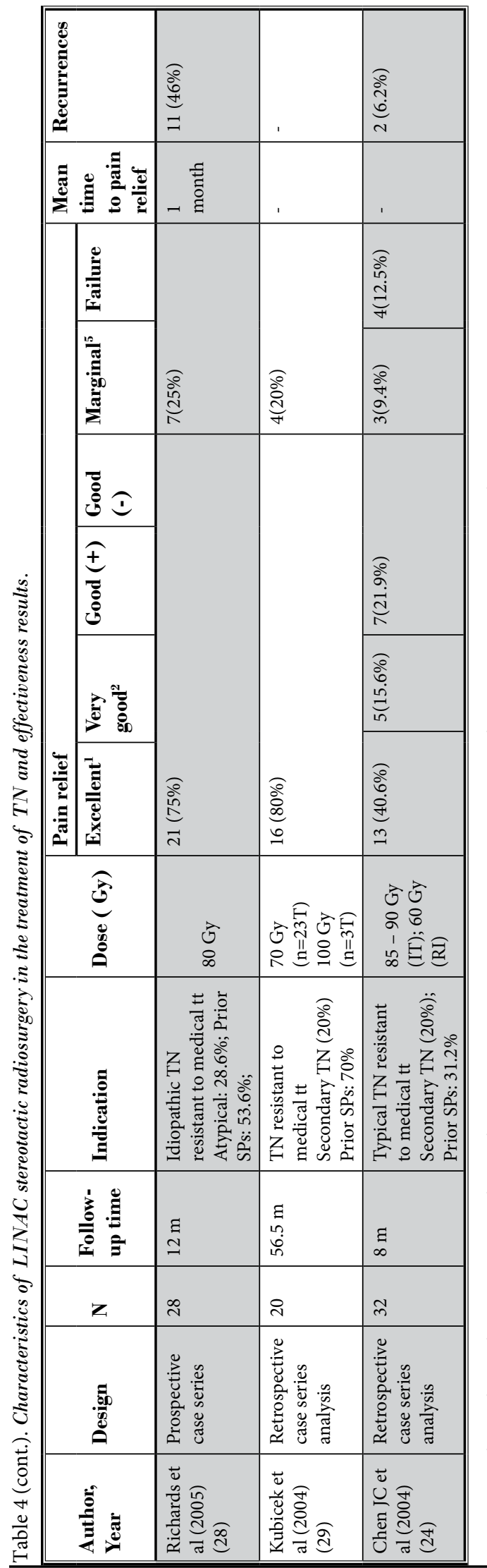

Zahra et al (26) published the previous year (2009) a review of the results of the first 20 patients treated at the Methodist Hospital in Houston (85-90Gy). After a mean follow-up of 14.2 months, substantial improvements were maintained in $95 \%$ of patients (BNI I: $40 \%$; BNI IIIA: 10\%; BNI IIIB: 35\%). Relief occurred in a mean time of 8.5 days.

The study by Pusztaszerit et al (27), carried out in 2007, reported the results of the first 17 cases intervened at the University Hospital of Lausanne (Centre Hospitalier Universitaire Vaudais/CHUV) in Switzerland (50Gy - 60Gy directed at a target $2-4 \mathrm{~mm}$ from the trigeminal nerve root). All patients experienced some improvement in pain: $35 \%$ achieved complete relief without medication; $35 \%$ presented with some occasional pain that did not require medication; and $29 \%$ suffered a relapse at $4-13$ months of follow-up.

In 2005, Richards et al (28) furnished data on 28 patients with idiopathic TN treated at the Medical College of Wisconsin (80Gy). After a mean follow-up of 12 months, $57 \%$ reported complete pain relief and $75 \%$ a reduction of 3 or more points on the pain scale. Mean time to pain relief was one month. The treatment failed in 4 patients.

Kubicek et al's study (29), dating back from 2004 , described the results of 20 of the first 26 patients with TN who were intervened at the University of Minnesota Medical Center from November 1996 to May 2003 (70Gy) and underwent long-term follow-up (56.5 months). The results were excellent to good in $80 \%$ of patients (complete relief without medication or pain reduction $\geq 50 \%$ ). The success rate was $100 \%$ in patients who had not undergone prior surgical interventions ( $n$ $=6$ ) and $71.4 \%$ in patients with prior surgical interventions $(n=14)$. Mean time to pain reduction was 97 days. The recurrence rate among patients who registered excellent results was $63 \%(5 / 8)$. Mean time of recurrence was 1.7 years.

\section{Safety Results}

All but 2 studies included in the systematic review $(24,27)$ recorded cases of facial numbness or hypoaesthesia (Table 5). The percentage of patients who suffered from facial numbness in the various series ranged from $7.5 \%$ to $50 \%$. On average, the frequency of numbness was $26.4 \%$.

Smith et al (20) categorized sensory loss on a 5-point scale (Table 6) based on the subjective assessment of patients during an interview and questionnaire and the results of a direct patient examination and found 


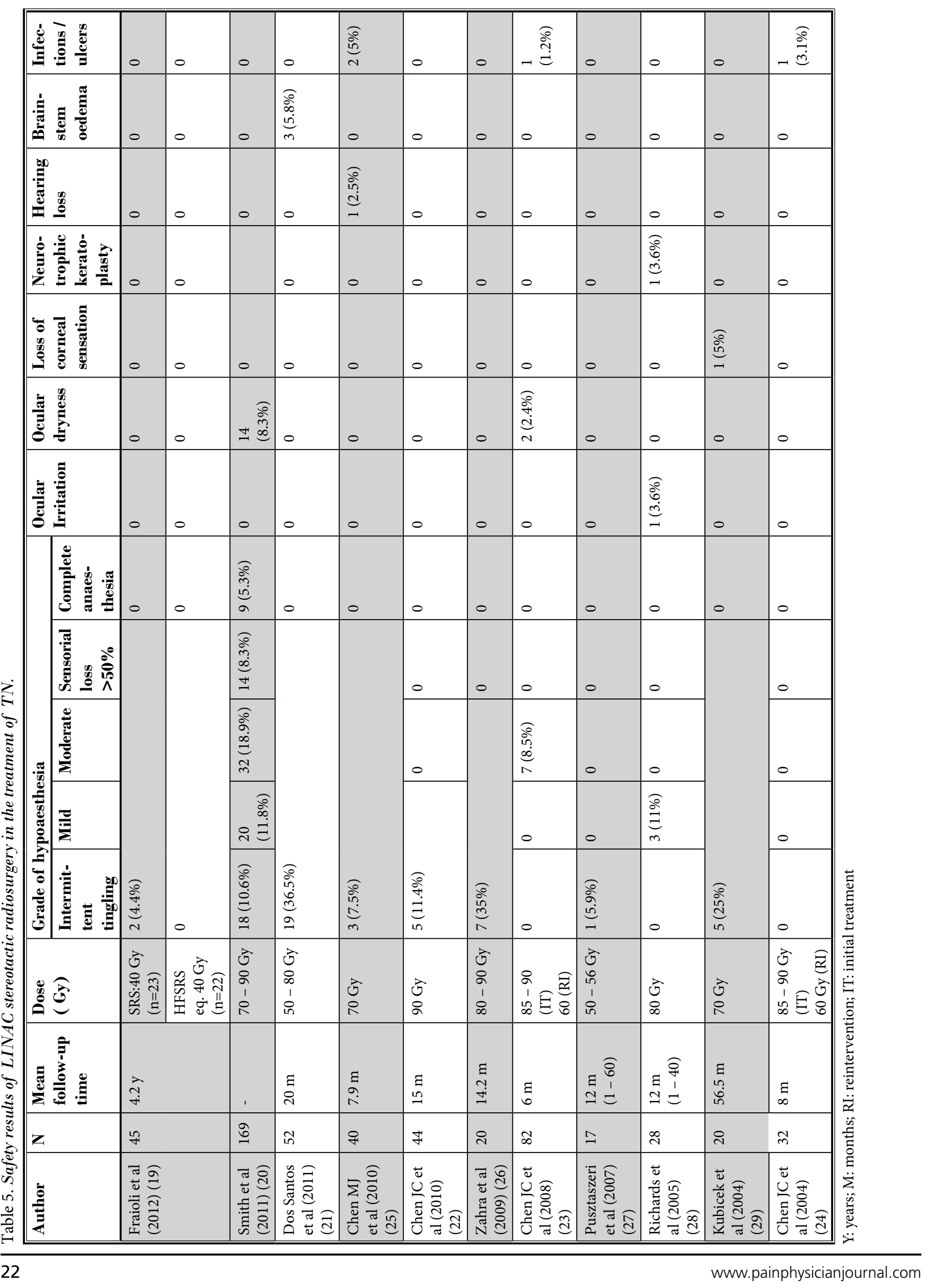


that $8.3 \%$ of patients presented grade 4 numbness (> $50 \%$ sensory loss, multiple divisions) and $5.3 \%$ grade 5 numbness (complete anaesthesia). There was facial numbness in $35.7 \%$ of patients treated with doses of $70-85 G y$, in $48.9 \%$ of those who received $90 \mathrm{~Gy}$ to the $30 \% \mathrm{IDL}$, and in $59.3 \%$ of those administered $90 \mathrm{~Gy}$ to the $50 \%$ IDL. There was grade $4-5$ numbness in $3.6 \%$, $10.6 \%$, and $17.8 \%$ of patients, respectively $(P<0.05)$. The remaining studies reported numbness of a mild to moderate nature. In the study by Fraioli et al (19), 8.7\% of patients treated with SRS versus $0 \%$ treated with HFSRS suffered from numbness.

The studies reviewed also reported cases of infections/ulcers resulting from the fitting of the invasive stereotactic frame $(1.2 \%-5 \%)(23-25)$ and certain ocular complications, such as dryness $(2.4 \%-8.3 \%)(20,23)$, irritation (11.2\%) (20), and loss of corneal sensation (5\%) (29). Isolated cases of hearing loss (2.5\%) (25) and brainstem oedema (5.8\%) (21) were also observed, and one study reported the appearance of neurotrophic keratoplasty (28) in one individual (3.5\%) who had undergone 5 prior surgical interventions.

\section{Quality and Level of Evidence}

All the studies located were case series, mostly retrospective and having small sample sizes $(<200$ patients). All studies were judged to present a high risk of bias as they did not include consecutive patients or specify inclusion/exclusion criteria. Studies were heterogeneous in terms of equipment, treatment guidelines, and selection of patients, making impossible the pooling of results and generating uncertainty regarding the reproducibility. Follow-up time proved insufficient for the purpose of assessing long-term effectiveness. The evidence was grade 3 according to the SIGN criteria for assignment of levels of evidence.

\section{Discussion}

The results of the systematic review indicate that stereotactic radiotherapy using LINACs could provide an acceptably safe and effective alternative for treatment of patients with drug-resistant TN. The studies report pain relief in $75 \%-95.7 \%$ of patients, with a very few severe complications $(<1 \%)$. However, all the studies retrieved were case series, mostly retrospective, single-center, and based on small-sized samples. The studies were heterogeneous in terms of equipment, treatment guidelines, and patient selection, thus generating uncertainty when it comes to the comparability
Table 6. Postoperative sensory grading scale.

\begin{tabular}{|l|c|}
\hline \multicolumn{2}{|c|}{ Sensory grade } \\
\hline Characteristic & Score \\
\hline$<\mathrm{TB}>$ Intermittent tingling, sensation intact & 1 \\
\hline Mild numbness, confined and intermittent & 2 \\
\hline Moderate numbness, confined and sustained & 3 \\
\hline$>50 \%$ Sensory loss, multiple divisions & 4 \\
\hline Complete anesthesia & 5 \\
\hline
\end{tabular}

Source: Smith ZA, et al. Dedicated linear accelerator radiosurgery for trigeminal neuralgia: A single-center experience in 179 patients with varied dose prescriptions and treatment plans. Int J Radiat Oncol Biol Phys 2011; 81:225-231 (20).

and generalizability of results.

Currently, different surgical alternatives are used to treat drug-resistant TNs, none of which are totally effective for relieving pain. In the light of the evidence furnished by several observational studies, MVD of the trigeminal nerve root is considered the most effective long-term technique (30-32). According to the results of a recent systematic review (7), this technique is successful in reducing pain in $90 \%-98 \%$ of cases and more than $60 \%-70 \%$ of patients remain pain-free at 10 years. However, since it is a technique that requires a craniotomy, it tends to be restricted to young patients (< 65 years) not posing a high surgical risk. Many authors and societies consider this technique the first-line of treatment for patients refractory to medical therapy $(1,3,9,14)$ and advocate the use of stereotactic radiosurgery or percutaneous procedures when patients are elderly, frail, or suffer from multiple sclerosis, recurrent pain after MVD, or contralateral hearing loss $(3,14)$. The guideline issued by the Subcommittee of the American Academy of Neurology (AAN) and the European Federation of Neurological Societies (EFNS) considers that the lack of direct comparative studies prohibits formal conclusions with regards to the use of any one of these alternatives and refers that all could be possibly effective for treating TN based on multiple Class III studies (Level C recommendation) (Table 7$)(2,3)$. It is suggested that the decision on the type of treatment should only be reached after the patient's physical condition has been analyzed and the different techniques, along with their advantages and disadvantages, have been presented to the patient. The literature makes reference to other encouraging treatment options, like neuromodulation, but there is lack of strong evidence that these can be offered on a regular basis to TN patients 
Table 7. EFNS Evidence classification scheme for a diagnostic measure.

\begin{tabular}{|c|c|}
\hline \multicolumn{2}{|c|}{$\overline{\text { LEVELS OF EVIDENCE }}$} \\
\hline Class I & $\begin{array}{l}\text { A prospective study in a broad spectrum of persons with the suspected condition, using a 'gold standard' for case } \\
\text { definition, where the test is applied in a blinded evaluation, and enabling the assessment of appropriate tests of diagnostic } \\
\text { accuracy. }\end{array}$ \\
\hline Class II & $\begin{array}{l}\text { A prospective study of a narrow spectrum of persons with the suspected condition, or a well-designed retrospective } \\
\text { study of a broad spectrum of persons with an established condition (by 'gold standard') compared to a broad spectrum } \\
\text { of controls, where test is applied in a blinded evaluation, and enabling the assessment of appropriate tests of diagnostic } \\
\text { accuracy. }\end{array}$ \\
\hline Class III & $\begin{array}{l}\text { Evidence provided by a retrospective study where either persons with the established condition or controls are of a narrow } \\
\text { spectrum, and where test is applied in a blinded evaluation. }\end{array}$ \\
\hline Class IV & Evidence from uncontrolled studies, case series, case reports, or expert opinion. \\
\hline \multicolumn{2}{|c|}{ GRADES OF RECOMMENDATION } \\
\hline LEVEL A & $\begin{array}{l}\text { Established as useful/predictive or not useful/predictive for a diagnostic measure or established as effective, ineffective } \\
\text { or harmful for a therapeutic intervention, and requires at least one convincing Class I study or at least two consistent, } \\
\text { convincing Class II studies. }\end{array}$ \\
\hline LEVEL B & $\begin{array}{l}\text { Established as useful/predictive or not useful/predictive for a diagnostic measure or established as effective, ineffective } \\
\text { or harmful for a therapeutic intervention, and requires at least one convincing Class II study or overwhelming Class III } \\
\text { evidence. }\end{array}$ \\
\hline LEVEL C & $\begin{array}{l}\text { Established as useful/predictive or not useful/predictive for a diagnostic measure or established as effective, ineffective or } \\
\text { harmful for a therapeutic intervention, and requires at least two Class III studies. }\end{array}$ \\
\hline LEVEL U & Not used \\
\hline $\begin{array}{l}\text { Good Clinical } \\
\text { Practice (GCP) } \\
\text { points }\end{array}$ & $\begin{array}{l}\text { Recommended best practice based on the experience of the guideline development group. Usually based on Class IV } \\
\text { evidence indicating large clinical uncertainty, such GCP points can be useful for health workers }\end{array}$ \\
\hline
\end{tabular}

Source: Cruccu G et al. AAN-EFNS guidelines on trigeminal neuralgia management. Eur J Neurol 2008; 15:1013-1028 (1).

(33). Lead mobility due to difficulty in anchoring the lead remains a significant barrier to the achievement of optimal results (3).

In general, the advantages of stereotactic radiosurgery are related to technique's minimal invasiveness. On the basis of the few comparative studies published on the GK, it is thought that this technique, while less effective than GR in terms of achieving an immediate pain relief could maintain a similar or longer lasting effect and present fewer side effects, with severe sensory deficits (anaesthesia dolorosa) or severe complications outside the trigeminal nerve (meningitis, masticatory dysfunction, keratitis) being very rare or non-existent. In a recent prospective observational study that assessed patients with multiple sclerosis-related TN (34), 100\% of patients treated with GR presented with immediate pain relief (BNI I-IIIb) versus $82 \%$ of patients treated with the $\mathrm{GK} 囚$, who displayed improvements in a mean time of 6 months. At a median follow-up time of 39 months, reasonable pain relief was achieved in $88.9 \%$ and $85.2 \%$ of the patients, respectively. Morbidity rate was $66.7 \%$ in the GR group (mostly hypalgesia, with 2 patients having corneal reflex loss and one meningitis) and $22.2 \%$ in the GK group (all sensory loss and pares- thesia). In a retrospective analysis of 188 patients who were not eligible for MVD (due to age, comorbidities, previous failure) (35), GR was similarly found to register a more immediate effect than did the GK® $(86 \%$ in $\leq 24$ hours versus $92 \%$ at 3 weeks), but patients experienced a significantly higher failure rates in the long-term (GR: $39 \%$, GK: $24 ; P=0.02)$ and more adverse side effects (54\% versus $30 \% ; P=0.019$ ). Pollock and Ecker (36) also failed to find a significant difference in facial pain relief between these 2 procedures $(P=0.61)$. Although no direct comparisons with GK have been found, a number of studies suggest that RFT could be superior to GR in terms of early and late rates of complete pain relief but this procedure is limited by the frequency and severity of side effects $(7,37,38)$. Balloon compression also has a good initial success rate but is deemed to present higher recurrence rates and severe complications when compared to other rhizotomy procedures $(9,39)$. Different studies have shown that, with current equipment, LINAC-based SRS can achieve a diagnostic accuracy and a dose distribution equivalent to that of the GK (40-42).

In view of the fact that LINACs are standard equipment in radiotherapy departments and can easily be adapted by merely incorporating a series of accessories, 
it is felt that this technique could provide an alternative to the GK, the equipment for which costs around $€ 4-€ 5$ million and solely covers intracranial lesions. However, possibly because the technique has historically been reputed to have less accuracy and precision in smallsized lesions, due to the higher rate of spatial errors caused by image fusion and rotation of the gantry and treatment table, there is little available evidence on treatment of TN and no ongoing studies have been identified despite the exhaustiveness of the search. Indeed, this is the first systematic review to be published on stereotactic radiosurgery using LINAC.

The conclusion to be drawn from the results of the current systematic review is that the effectiveness of LINAC-based SRS could be equal or even superior to that of the GK. The success rate recorded in the current series $(75 \%-95.7 \%)$ is similar to that described in the series published on the GK, and the recurrence rates point to a more prolonged duration of the effect. In Smith et al's prospective series (20), pain relief was maintained by $93.9 \%$ of patients at one year and $82.6 \%$ at 3 years. Chen et al (22) reported a recurrence-free rate of $78 \%$ at one year. In the GK series, the recurrence rates at $2-3$ years were in the order of $40 \%-55 \%$ $(32,43,44)$. The recurrence rate at 5 years was $33 \%-$ $34 \%(32,44)$. However, since all these are heterogeneous case series that are mostly retrospective and came from isolated health centers, it is difficult to ascertain to what extent these differences might be related to the differential characteristics of the 2 stereotactic devices or, in contrast, might be the consequence of differences in indication, technique, or treatment protocol. Without comparative randomized studies it is impossible to draw solid conclusions about the equivalence of both types of treatment.

Overall, severe adverse effects are extremely infrequent $(>1 \%)$, though one of the series observed complete anaesthesia in $5.3 \%$ of patients and another reported brainstem oedema in 5.8\%. Dos Santos et al (21) attributed the cases of brainstem oedema to the use of 2 collimators instead of one, and ceased to use them after the appearance of the 3 cases. In the study conducted by Smith et al (20), severe numbness was associated with a change in the treatment protocol (from the $30 \%$ IDL to the $50 \%$ IDL), which is why the authors suggest that it might be wiser for the radiation to be targeted at the aortic root. Fraioli et al (19) propose that the same effectiveness can be achieved at very low doses (40Gy), if the treatment is directed at the retrogassarian portion of the nerve, thereby significantly reducing adverse effects. Similarly, Pusztaszerit et al (27) describe a high degree of effectiveness with low doses (50 - 56Gy) directed at a target located $2-4 \mathrm{~mm}$ from the trigeminal root entry. The wide heterogeneity of these results clearly suggests that there is a need for comparative studies purposely designed to assess the impact had by these and other aspects on effectiveness and safety. For instance, research should be conducted into the influence exerted by the different image-acquisition systems, the planning of LINAC systems, multileaf collimation, fractionated treatment administration (45), and the application of radiosurgery without a fixed stereotactic frame. It has been suggested that the newest generation LINAC units might be more precise and safer than previous systems but this remains to be verified by appropriately designed studies.

Clarification is also required to clear up doubts regarding the criteria for eligibility for this technique. Two of the studies included $(20,29)$ ( $n=205$ patients) suggest that patients with essential TN yield better results than do patients with secondary TN (good or excellent response: $80 \%-88.5 \%$ versus $39.3 \%-50 \%$ ), and establish that effectiveness is also worse in patients with prior interventions and very low in patients with atypical pain (27.3\%). In contrast, another 2 studies which performed a multivariate analysis to assess which factors might influence patient response $(21,23)$ ( $n=$ 134 patients), showed no significant correlation with the pattern of pain or the application of prior surgical procedures.

\section{Conclusions}

In summary, the results suggest that stereotactic radiosurgery with LINACs could constitute an effective and safe therapeutic alternative for treating patients with drug-resistant TN. The evidence indicates that success could be similar or even greater than that achieved with the GK but, since there are no randomized clinical trials, it is impossible to establish the true effectiveness and safety with regards to this technique or other available surgical procedures (percutaneous rhizotomy or MVD). Based on indirect comparisons, LINAC-based SRS is thought to be possibly less effective in terms of immediate pain relief but safer than percutaneous rhizotomy, with severe sensorial deficits or complications outside the trigeminal distribution being less frequent. MVD yields better long-term results and seems to be the preferred option for patients whose risk for general anaesthesia is acceptable. However, evidence is clearly insufficient 
to favor a particular technique. Taking into account the available literature, we consider that the selection of patients should be made taking into account the underlying pathophysiology, patient's preferences, the risks he or she is willing to assume, the availability of the technique in the center, and the team's experience (level 3, grade D). With respect to LINAC-based SRS, current equipment in radiotherapy departments could be easily adapted.

Existing studies leave important doubts as to optimal treatment doses, sequence of lesioning or therapeutic target, and do not help identify which subgroups of patients could most benefit from this technique. With a view to drawing up indications for use, we thus feel that prospective randomized trials should be undertaken to enable clarification of existing doubts and verification of long-term recurrence.

\section{References}

1. Cruccu G, Gronseth G, Alksne J, Argoff C, Brainin M, Burchiel K, Zakrzewska JM; American Academy of Neurology Society; European Federation of Neurological Society. AAN-EFNS guidelines on trigeminal neuralgia management. Eur J Neurol 2008; 15:1013-1028.

2. García Hernández MG, Sánchez Rodríguez JP, Tenopata Villegas S. Neuralgia del Trigémino. An Med (Mex) 2012; 57:39-47.

3. van Kleef $M$, van Genderen WE, Narouze S, Nurmikko TJ, van Zundert J, Geurts JW, Mekhail N; World Institute of Medicine. 1. Trigeminal neuralgia. Pain Pract 2009; 9:252-259.

4. Manzoni GC, Torelli P. Epidemiology of typical and atypical craniofacial neuralgias. Neurol Sci 2005; 26:S65-S67.

5. Gronseth G, Cruccu G, Alksne J, Argoff C, Brainin M, Burchiel K, Nurmikko T, Zakrzewska JM. Practice parameter: The diagnostic evaluation of treatment of trigeminal neuralgia (an evidence-based review). Neurology 2008; 71:1183-1190.

6. Robaina Padron FJ. Trigeminal neuralgia. A review of the medical a surgical management. [Spanish]. Neuralgia del trigemino. Revision del tratamiento medico y quirurgico. Rev Soc Esp Dolor 2008; 15:248-256.

7. Lopez BC, Hamlyn PJ, Zakrzewska JM. Systematic review of ablative neurosurgical techniques for the treatment of trigeminal neuralgia. Neurosurgery 2004; 54:973-983.

8. Lopez BC, Hamlyn PJ, Zakrzewska JM. Stereotactic radiosurgery for primary trigeminal neuralgia: State of the evidence and recommendations for future reports. J Neurol Neurosurg Psychiatry 2004; 75:1019-1024.

9. Cheng JS, Lim DA, Chang EF, Barbaro NM. A review of percutaneous treatment for trigeminal neuralgia. Neurosurg 2013; Epub ahead of print.
10. Toda K. Operative treatment of trigeminal neuralgia: Review of current techniques. Oral Surg Oral Med Oral Pathol Oral Radiol Endod 2008; 106:788-805.

11. Artico M, De Caro GM, Fraioli B, Giuffre R. 1897 - celebrating the centennial - Hermann Moritz Gocht and radiation therapy in the treatment of trigeminal neuralgia. Acta Neurochir 1997; 139:761-763.

12. Cole CD, Liu JK, Apfelbaum RI. Historical perspectives on the diagnosis and treatment of trigeminal neuralgia. Neurosurg Focus 2005; 18: $\mathrm{E}_{4}$.

13. Dhople AA, Adams JR, Maggio WW, Naqvi SA, Regine WF, Kwok Y. Longterm outcomes of Gamma Knife radiosurgery for classic trigeminal neuralgia: Implications of treatment and critical review of the literature. J Neurosurg 2011; 115:125-132.

14. International RadioSurgery Association. Stereotactic radiosurgery for patients with intractable typical trigeminal neuralgia who have failed medical management [Internet]. Radiosurgery Practice Guideline Report \#1-03. 2009.

15. Lim JNW, Ayiku L. Systematic review of the clinical efficacy and safety of stereotactic radiosurgery (gamma knife) in the treatment of trigeminal neuralgia. Review Board for Interventional Procedures, University of Sheffield, 2004.

16. Frighetto L, De Salles AA, Smith ZA, Goss B, Selch M, Solberg T. Noninvasive linear accelerator radiosurgery as the primary treatment for trigeminal neuralgia. Neurology 2004; 62:660-662.

17. Viswanathan M, Ansari MT, Berkman ND, Chang SD, Hartling L, McPheeters LM, Santaguida PL, Shamliyan T, Singh K, Tsertsvadze A, Treadwell JR. Assessing the risk of bias of individual studies in systematic reviews of health care interventions. Agency for Healthcare Research and Quality Methods Guide for Compara- tive Effectiveness Reviews: AHRQ Publication, March 2012.

18. Harbour R, Miller J. A new system for grading recommendations in evidence based guidelines. Br Med J (Clin Res Ed) 2001; 323:334-336.

19. Fraioli MF, Strigari L, Fraioli C, Lecce M, Lisciani D. Preliminary results of $45 \mathrm{pa}-$ tients with trigeminal neuralgia treated with radiosurgery compared to hypofractionated stereotactic radiotherapy, using a dedicated linear accelerator. J Clin Neurosci 2012; 19:1401-1403.

20. Smith ZA, Gorgulho AA, Bezrukiy N, McArthur D, Agazaryan N, Selch MT, , De Salles AA. Dedicated linear accelerator radiosurgery for trigeminal neuralgia: A single-center experience in 179 patients with varied dose prescriptions and treatment plans. Int J Radiat Oncol Biol Phys 2011; 81:225-231.

21. Dos Santos MA, Perez de Salcedo JB, Gutierrez Diaz JA, Nagore G, Calvo FA, Samblas J, Marsiglia H, Sallabanda K. Outcome for patients with essential trigeminal neuralgia treated with linear accelerator stereotactic radiosurgery. Stereotact Funct Neurosurg 2011; 89:220-225.

22. Chen JC, Rahimian J, Rahimian R, Arellano A, Miller MJ, Girvigian MR. Frameless image-guided radiosurgery for initial treatment of typical trigeminal neuralgia. World Neurosurg 2010; 74:538-543.

23. Chen JC, Greathouse HE, Girvigian MR, Miller MJ, Liu A, Rahimian J. Prognostic factors for radiosurgery treatment of trigeminal neuralgia. Neurosurgery 2008; 62:A53-A6o; discussion A60-A61.

24. Chen JC, Girvigian M, Greathouse $H$, Miller M, Rahimian J. Treatment of trigeminal neuralgia with linear accelerator radiosurgery: Initial results. J Neurosurg 2004; 101:346-350.

25. Chen MJ, Shao ZY, Zhang WJ, Wang $\mathrm{ZH}$, Zhang WH, Hu HS. X-knife ste- 
reotactic radiosurgery on the trigeminal ganglion to treat trigeminal neuralgia: A preliminary study. Minim Invasive Neurosurg 2010; 53:223-228.

26. Zahra H, Teh BS, Paulino AC, Yoshor D, Trask T, Baskin D, Butler EB. Stereotactic radiosurgery for trigeminal neuralgia utilizing the BrainLAB Novalis system. Technol Cancer Res Treat 2009; 8:407-412.

27. Pusztaszeri M, Villemure JG, Regli L, Do HP, Pica A. Radiosurgery for trigeminal neuralgia using a linear accelerator with BrainLab system: Report on initial experience in Lausanne, Switzerland. Swiss Med Wkly 2007; 137:682-686.

28. Richards GM, Bradley KA, Tome WA, Bentzen SM, Resnick DK, Mehta MP. Linear accelerator radiosurgery for trigeminal neuralgia. Neurosurgery 2005; 57:1193-1199.

29. Kubicek GJ, Hall WA, Orner JB, Gerbi BJ, Dusenbery KE. Long-term follow-up of trigeminal neuralgia treatment using a linear accelerator. Stereotact Funct Neurosurg 2004; 82:244-249.

30. Tronnier VM, Rasche D, Hamer J, Kienle AL, Kunze S. Treatment of idiopathic trigeminal neuralgia: Comparison of long-term outcome after radiofrequency rhizotomy and microvascular decompression. Neurosurgery 2001; 48:12611267; discussion 1267-1268.

31. Brisman R. Microvascular decompression vs. gamma knife radiosurgery for typical trigeminal neuralgia: Preliminary findings. Stereotact Funct Neurosurg 2007; 85:94-98.

32. Linskey ME, Ratanatharathorn $V$ Penagaricano J. A prospective cohort study of microvascular decompression and gamma knife surgery in patients with trigeminal neuralgia. J Neurosurg 2008; 109:160-172.

33. Monsalve GA. Motor cortex stimulation for facial chronic neuropathic pain: A review of the literature. Surgical Neurology International 2012; 3:S290-S311.

34. Mathieu D, Effendi K, Blanchard J, Seguin M. Comparative study of gamma knife surgery and percutaneous retrogasserian glycerol rhizotomy for trigeminal neuralgia in patients with multiple sclerosis. J Neurosurg 2012; 117:175-180.

35. Henson CF, Goldman HW, Rosenwasser $\mathrm{RH}$, Downes MB, Bednarz G, Pequignot EC,Werner-Wasik M, Curran WJ, Andrews DW. Glycerol rhizotomy versus gamma knife radiosurgery for the treatment of trigeminal neuralgia: An analysis of patients treated at one institution. Int J Radiat Oncol Biol Phys 2005; 63:82-90.

36. Pollock BE, Ecker RD. A prospective cost-effectiveness study of trigeminal neuralgia surgery (structured abstract). Clin J Pain 2005; 4:317-322.

37. Udupi BP, Clouhan RS, Dash HH, Bithal PK, Bithal PK, Prabhakar H. Comparative evaluation of percutaneous retrogasserian glycerol rhizolysis and radiofrequency thermocoagulation techniques in the management of trigeminal neuralgia. Neurosurg 2012; 70:407-413.

38. Fraioli B, Esposito V, Guidetti B, Cruccu $G$, Manfredi M. Treatment of trigeminal neuralgia by thermocoagulation, glycerolization, and percutaneous compression of the gasserian ganglion and/ or retrogasserian rootlets: Long-term results and therapeutic protocol. Neurosurgery 1989; 24:239-245.

39. Kouzounias K, Lind G, Schechtmann G Winter J, Linderoth B. Comparison of percutaneous balloon compression and glycerol rhizotomy for the treatment of trigeminal neuralgia. J Neurosurg 2010;
113:486-492.

40. Ma L, Kwok Y, Chin LS, Yu C, Regine WF. Comparative analyses of linac and gamma knife radiosurgery for trigeminal neuralgia treatments. Phys Med Biol 2005; 50:5217-5227.

41. Rahimian J, Chen JC, Rao AA, Girvigian MR, Miller MJ, Greathouse HE. Geometrical accuracy of the Novalis stereotactic radiosurgery system for trigeminal neuralgia. J Neurosurg 2004; 101:351-355.

42. Gerbi BJ, Higgins PD, Cho KH, Hall WA. Linac-based stereotactic radiosurgery for treatment of trigeminal neuralgia. J Appl Clin Med Phys 2004; 5:80-92.

43. Pollock BE, Phuong LK, Gorman DA, Foote RL, Stafford SL. Stereotactic radiosurgery for idiopathic trigeminal neuralgia. J Neurosurg 2002; 97:347-353.

44. Dhople AA, Adams JR, Maggio WW, Naqvi SA, Regine WF, Kwok Y. Longterm outcomes of gamma knife radiosurgery for classic trigeminal neuralgia: Implications of treatment and critical review of the literature - Clinical article. J Neurosurg 2009; 111:351-358.

45. López-Pedraza Gómez MJ, Calcerrada Díaz-Santos N, Blasco Amaro JA. Systematic review on the efficacy and safety of ciberknife: Indications and results in the treatment of intra and extra craneal lesions. Plan de Calidad para el Sistema Nacional de Salud del Ministerio de Sanidad y Política Social. Unidad de Evaluación de Tecnologías Sanitarias, Agencia Laín Entralgo; 2009. Informes de Evaluación de Tecnologías Sanitarias. UETS 2007/3.

46. Scottish Intercollegiate Guidelines Network. Forming guideline recommendations. In: SIGN 50: A Guideline Developers' Handbook. SIGN, Edinburgh, 2011. 
